\title{
The Design of Intellectual Experience
}

\section{Donald L. Finkel and G. Stephen Monk}

Sharing experiences with students is essential tolearning, but difficult to accomplish. The authors suggest a workshop approach, give a detailed example, and discuss basic principles for worksheet design.

\section{Why Teach?}

Beneath the conscious goals and motivations that drive a teacher's daily activities lies a basic human impulse: the desire to share intellectual experiences. Most teachers have felt for themselves the striking pleasure that results from the work of intelligence, whether experienced as insight, beauty, connectedness, or resolution. Ideally, they would like to lead their students to such pleasures; yet, the accomplishment of this ideal is rare.

Few teachers adopt the explicit goal of sharing experience, and those who do must be struck by the difficulty of actively pursuing such an aim. This is not the sort of pedagogic goal about which one's colleagues talk. Moreover, what kind of methods could be formulated for achieving such a personal and insubstantial goal? Too easily, the dimension of experience is ignored altogether, leaving teachers with only the products of their disciplines to present. Yet, it is the processes that lead to these products which yield the intellectual excitement they wish to share. For students to experience such excitement, the formal systems of knowledge must be undone, so that students can feel what it is like to put those systems together for themselves. Thus, teachers must learn how to convert academic subject matter into activities for 
students. Because it is just these intellectual activities that lead to understanding, the students' gains and the teachers' gratification stem from the same process.

This article will describe a framework for converting formal knowledge into structured activities for students. We shall examine an example and draw from it six principles for designing such activities. This discussion should make concrete the goal of sharing intellectual experience and indicate its benefits to both students and teachers. We must begin, however, by confronting the dilemma which faces any teacher who takes this goal seriously.

\section{The Dilemma of Sharing}

Suppose you return home from a trip to Nepal. You are brimming with the excitement of the experience and wish to share it with your friends. Your first inclination is to describe to them in detail all you can about the people, the landscape, and the customs, illustrating your adventures with as many slides as possible. Your first impulse is the Impulse to Tell. After several hours of slides and talk, you cannot avoid a conclusion: Since your friends have never experienced anything like Nepalese culture, they cannot possibly get from your description what you feel you are putting into it, or anything like what you got from the trip.

Perhaps it is impossible to tell about important experiences, to give them directly to others. Maybe you should wait until your friends' lives naturally take them to Nepal. Then, when they return, you will finally be able to share the experience. The Impulse to Tell has given way to the Impulse to Let It Happen. Following this impulse is not satisfying either, since you may have to wait forever, and you want to share your trip now. Compromises are possible, and you may urge your friends to travel. Yet even if amenable, they will probably experience Nepal quite differently. More likely, however, your urging will awaken a long buried desire in them for travel up the Nile, and then you will be faced with the inevitable evening of Egyptian slides and monologues.

These two opposing impulses. The Impulse to Tell and the Impulse to Let it Happen, are inherent in the attempt to share experiences, and each has the unfortunate tendency to drive you to an extreme. If 
you sense you are telling unsuccessfully, you are likely to tell more and more, and to tell in greater and greater detail. If you withdraw to let something happen, careful to avoid imposing your own experience on others, and nothing happens, then you will withdraw even further to leave a wider arena free for the others' experience. The dilemma of sharing is this: What do you do when you have discovered that neither telling nor refraining from telling is a successful mode of sharing?

Teachers also find themselves caught in this dilemma. In the classroom, the Impulse to Tell leads to lecturing or expository methods of presenting subject matter. The Impulse to Let It Happen is found in various non-directive teaching modes that have arisen in reaction to exposition. We do not oppose these forms in themselves but rather the results that flow from them. Teachers who seek change by following one of these impulses find themselves either expounding in ever more exquisite detail or refining even further the role of non-leader. Since telling doesnot provide a genuine experience and letting things happen does not produce the particular experience you had in mind, neither of these impulses leads to the genuine satisfaction that comes form sharing an intellectual experience.

\section{Sharing Intellectual Experiences}

The solution to the dilemma lies in the intriguing possibility that a teacher can design an experience which has intellectual consequences for students, the very consequences the teacher wished to share in the first place. Our central thesis is that such pedagogic activity is possible and that teachers can best share intellectual experiences by designing them.

This claim immediately raises two questions. What are intellectual experiences and what does it mean to share them? Does going to a Beethoven concert with your friend constitute sharing an intellectual experience? What about watching a football game together? Returning to the previous example concerning the trip to Nepal, you cannot be sure that even bringing your friends with you to Nepal would have satisfied your desire to share the experience. To address these questions, we must distinguish between the external events or objects (the musicians, the musical sounds, the football game, the people of Nepal) 
from what we make of them (our perceptions, ideas, interpretations). These mental constructs are what we use to interact with the external events; without them we can have no experience. Thus, events in themselves are neither intellectual nor non-intellectual. These terms refer only to the nature of our interactions with events. Interactions may be characterized as more intellectual to the degree that they engage and promote the development of more elaborate and comprehensive systems of ideas. Listening to Beethoven can be non-intellectual depending upon how one is listening, while watching a football game might be a most intellectual activity if were part of a comparative analysis of games.

Now, what does it mean to share an intellectual experience? Suppose you are listening to a record of a Beethoven quartet with which you are not familiar, and you suddenly become aware of a structural similarity among all of Beethoven's late quartets. Full of excitement, you invite a friend over to hear your new record. You have had an intellectual experience and wish to share it. As you listen to the record together, are you sharing an intellectual experience? It is most unlikely that your friend will make the same discovery you made by just listening to the record. When the record ends you look at your friend expectantly to see if "it happened," and then you recall that for a teacher to merely expose students to archetypal examples is precisely to yield to the Impulse to Let It Happen. It is tempting to think that something fruitful must result from such exposure. After all, how could one read Shakespeare and not be improved by the experience? However, teachers who simply trust in such invisible and delayed effects forgo a sense of direct contribution to their students' understanding. Implicit in the idea of sharing is that we teachers have something valuable to give, not Beethoven or Shakespeare, but ways of thinking about them, ways of understanding and ultimately of interacting with music and words. We would like to give our students the systems of ideas, the perspectives, the concepts that make possible these interactions with music and words. Yet, to adopt such an approach sounds as though we are back to Telling. If only we could collar our students, reach into their heads with a mental hand, and alter their patterns of thought! Once again, we face the dilemma of sharing. 
To resolve this dilemma, we must focus on two crucial propositions about these patterns of thought we would like to alter. First, there is no way to interact intellectually with anything in the environment except through such mental patterns. Every student brings some form of conceptual system to new material; the student initially understands the material in the best way he or she can, interpreting it according to his or her present patterns of thought. This proposition is encouraging because it means the teacher is not attempting to get students to elaborate complex theories from nothing. It can also be discouraging, because it means that the teacher must work with students' systems no matter how primitive, fuzzy or ill-conceived those systems may seem when compared to the system the teacher would like the students to develop. The second proposition is that the structure of the system of ideas which engages with an external event will never match perfectly with the structure of the event. One's own mental system will inevitably influence the way one "sees" the event. At the same time, interaction with the event can influence the system of ideas.

It is possible to influence someone else's patterns of thought by means less direct than a mental hand. The teacher can design an environment, and activities for students within that environment, which will engage their current conceptual systems in such a way that these systems will be induced to develop. These activities must aim to create a kind of mismatch between internal structure and external event that leads the student to refine, differentiate, and restructure the conceptual system. This approach to teaching is neither Telling nor Letting It Happen. In designing such experiences for students, the teacher must draw upon personal intellectual experiences, but the students will have their own experiences in working through the activities. No one can directly engineer an experience or guarantee the outcome for another person. However, designing focused activities within a concrete environment makes the chances of converging experiences likely, and such a convergence is as close as we can come to sharing.

We thus propose designing intellectual experiences for students as a means for sharing the pleasures of the mind with them. To design, in this sense, is to structure a specific environment for student interaction in order to promote the restructuring of the students' systems 
of ideas. We take the goal of conceptual restructuring to be of paramount importance because it is the students' systems of ideas that stay with them and shape their vision of the world. Moreover, it is the act of restructuring such systems which provides the pleasures of intellectual work we assume teachers wish to share with their students.

\section{An Example}

The most prominent feature of teacher-designed intellectual experiences, or "workshops" as we call them, is that students work on their own in groups ranging in size from two to seven. The teacher roves from group to group, observing, guiding, questioning, and "teaching," in response to the needs of specific groups or individuals. The students' work is directed by a set of written instructions and questions which we call a "worksheet." Thus, the teacher is present in the students' environment only through the written worksheet and occasional interactions.

The following worksheet is for a college-level workshop in developmental psychology, sociology, or the philosophy of education. The intellectual experience it attempts to share is the understanding that the way one thinks about child development is inextricably linked to one's conception of society. The authors hoped to induce their students to make this connection and to crystallize it by formulating alternative versions of the possible relations between society and the developing child.

There are four parts to the worksheet. As you read them, try to picture a classroom full of students engaged in these activities. Further, try to determine how each part of the worksheet requires a different style of work from the students. Finally, ask yourself these questions: Is the worksheet likely to engage the students' current patterns of thought about development and society? Is it likely to result in a restructuring of the students' ideas on this topic?

\section{Eloise and the Philosophers}

There are four parts to this workshop. Part I is to be performed in pairs. Parts II and III are to done in groups of six, formed by combining 
three of the previous partnerships from Part I. Part IV will be completed with the class together as a whole.

Part I Eloise is an 11-year-old girl who has decided to keep a diary during her sixth-grade year, which she has just begun. You will find attached the first entry in her new diary, written during the lunch hour of the first day of school. After reading the entry [which appears below, after Part IV], agree on and write down the answers to the following five questions.

1. List the five different activities in which Eloise participated during her morning.

2. For each activity, describe what you think were the teacher's underlying goals (or strategies) in having the children participate in such an activity.

3. Now consider that the school and its teachers are primarily agents of society, and that one of society's tasks is to employ the school to affect children's emotional and intellectual development in such a way that they are prepared to enter society and be useful members. Then each of Eloise's activities can be viewed as meeting society's goals well or badly, but on two levels: on the level of content (fractions, writing skill, ecology, etc.) and on the level of form (the way the activity is organized.) Ignoring the content of Eloise's morning, describe how society is affecting her through the form of each of the activities. Why is each activity structured the way it is?

4. Note the basic similarities and differences among the five activities, based upon your responses to question 3. Overall, do the forms of the different activities tend to be consistent with each other, or inconsistent?

5. What are some different ways to view the possible relationship between the developing child and society? List at least three different relationships.

Part II Form groups of six by combining three partmerships. Each group should choose a scribe to keep a written record of results. The group will be given a set of 14 index cards, each with a quota- 
tion on it. [See below for example]. These quotes are from philosophers and educators, old and new.

1. Each quote implies a certain relationship between the developing child and society. Sort the quotes into a small number of categories (between 3 and 5) that reflect the differing relationships. Try to agree on the groupings.

2. Formulate and agree upon descriptive labels for each of your categories.

You will probably have to go back and forth between questions 1 and 2, sorting some cards, deciding upon a tentative label, and resorting some of the original cards. If you cannot reach agreement, record minority opinions.

Part III Remain in the same group of six.

1. Together with your original partner from Part I, share your answers to Part I, question 5, with the group. Compare these answers to the categories your group devised in Part II. Did categorizing the quotes alter your original views significantly? If so, in what ways? Compare the effects of Part II on your views with its impact on other partnerships in your group, and have the scribe record general trends.

2. Using your current set of categories from Part II, your group should place each of the following systems into the appropriate category.

(a) Summerhill (as seen in the film last week),

(b) the school you are now attending,

(c) the way your parents treated you (in general),

(d) the way you intend to treat your children,

(e) today's workshop

Part IV The class will reassemble as a whole. We will hear the results of each group's work from the scribes, and then discuss the entire exercise.

\section{Eloise's Diary}

Dear Diary: It was great to get back to school and see my friends again, especially Susan. Before the bell rang, I told her all about our 
summer trip to Mexico, and about Manuel, and our trip to the beach together. This year I got Mrs. Morgan. She's okay, but I wanted Mr. Brown. Susan's so lucky she got him! After attendance the first thing we had to do was write a paper about what we did over summer vacation. Why do teachers always give that dumb assignment? Well, I wrote about Mexico City, and the market place, about all the things you can buy there. Some people read their papers out loud, but I didn't. Then we had math. Mrs. Morgan explained about multiplying and dividing fractions. We had all that stuff last year, but no one seems to remember it. Even Mrs. Morgan made a mistake at one point! Of course, everybody loved that. We learned a little poem, so we know when to flip the fraction upside down, and when not to. (I forgot the poem already! I never was good in math!!) Then we saw a movie about a lake in Africa-like the ones on TV. Mrs. Morgan said for science we are going to learn a new thing called ecology. The first thing we had to do was list all the animals we saw using the lake and tell how they used it. Then Mrs. Morgan asked us what would happen to all the plants and animals if the hippos got killed and could never bathe in the lake. Richard said there would be a lot of dead hippos around and the whole class laughed. Richard's so dumb! But Mrs. Morgan would$n ' t$ tell us the answer, even after we tried. Then we had gym. I love gym, but Mr. Brown's class creamed us in volleyball. If only I could get those creeps in our class to set up the ball, I'm sure we could win. When we got back, there was a policeman waiting in our room. Everyone was excited for a minute, but it turned out to be a lecture on drugs. He showed us all these pills and needles and stuff and said it was all bad. Borrring! Now it's lunch time. Oh, here comes Susansee you tonight. Diary.

\section{Sample Quotes}

[We include the following three quotations to give the reader of this article a flavor of the quotations used. We have chosen three rather extreme cases, but the full group of 14 index cards presents a formidable task of differentiation and categorization.] 
"Give your scholar no verbal lessons; he should be taught by experience alone; never punish him, for he does not know what it is to do wrong;....May I venture at this point to state the greatest, the most important, the most useful rule of education? It is: Do not save time, but lose it.

"Having thus very early set up your Authority, and by the gentler Applications of it, shamed him out of what leads towards any immoral Habit... (for I would by no means have chiding used, much less Blows, till Obstinacy and Incorrigibleness make it absolutely necessary)..."

"What is the least that we can say about an organism's development? Everybody admits that two things must be said: First, it develops by getting habits formed; and second, it develops by getting new adaptations which involve the breaking up or modification of habits."

To appreciate the experiential flavor of the workshop, you should now switch gears and actually do the problems which make up Part I. Readers usually tend to resist becoming more active in this way, but you will sense the power of this approach only if you overcome this resistance.

\section{Principles of Design}

The most striking quality of this worksheet on first reading is its variety. The students work in pairs, groups, and as a whole class. They read the imaginary diary of a sixth grader and later classify quotes from philosophers. In addition to reading and sorting cards, they must express themselves to classmates, argue for their views, and reflect upon their own experiences. In order to reveal the orderly design within this apparent kaleidoscope of educational activities, we must bread down the overriding goal of workshops into a set of interlocking principles. Recall that the teacher's goal is to convert an intellectual product into a sequence of activities for students. The six principles that follow will suggest how such a conversion may be facilitated and will illustrate why the authors of the previous worksheet designed it as they did. 
A worksheet must always set forth an environment, and activities for students in that environment, which engage their current conceptual systems in such a way that these systems will be induced to develop. We will first examine the nature of that environment, then describe the structure of the activities, and finally discuss the resulting role of the teacher. Our six principles emerge from the discussion of these three elements of workshops. They are italicized in the text and summarized in a list at the end of this section.

Environment. The student's environment in a workshop has two chief components: an external shared event and the other students in the group. The external event can take many forms; in the above example it was Eloise's diary and then the quotes on index cards. Whatever the form, the event must be specific, concrete, and present. These features are required to engage effectively the students' conceptual systems. Any material (texts, data, graphs, journals) with which the students are going to work must be ready at hand in manageable quantities. The material must be sufficiently challenging to engage the students at diverse levels of sophistication, but not so complicated as to overwhelm them.

The group of students working together on a worksheet provides a second aspect of the environment. Students can help one another in a number of ways: They can provide mutual support and a sense of common purpose; their exchanges can promote the externalization and articulation of ideas; finally, the diversity of points of view provides a continuing source of puzzlement and constructive friction. This last feature of group work propels the card sorting task in Eloise, while externalization and clarification of ideas lies behind the use of partnerships in Part I, the analysis of the diary. The teacher designing a workshop must think through these issues in advance in order to exploit consciously the collective potential of the group. Such devices as requiring agreement, fostering debate, inviting exchange of work, and assigning specialized roles use the group productivity. With whatever techniques you use, your instructions must implicitly communicate your trust in your students' capacity as a group and your genuine expectation that together they have the resources to complete the task. 
However, simply to place your students on their own in groups to explore a stimulating event is insufficient. Beyond the group and the event, a third aspect of the environment is required. Specific questions and instructions must be written in advance and given to each student. These questions and instructions constitute the worksheet itself. Sometimes the activities required will not be clear unless they are written. Even when the instructions could be communicated orally or on the board, it is important to distribute them to each student. With the worksheet at hand, the students can interact directly with the event and each other without the need for the teacher's constant personal mediation. These written questions and instructions embody the teacher's wisdom on the subject, yet in this form, they permit the students to take the initiative.

Activities. A great deal of activity can be generated by placing students in an environment that contains concrete events, other students, and specific written questions about these events. However, student activity in itself is not our goal. We wish to induce intellectual change in order to allow the sharing of intellectual experience. To effect intellectual change, the activity must have a particular structure. This structure may be summarized by saying that every worksheet requires the students to solve a problem.

The best way to alter someone else's thought is to provide a problem which cannot be solved with his or her present conceptions. This requires a three-phase process. First the student must be made to see the problem as a genuine problem that is disturbing and requires resolution. Such a problem must be formulated from the student's own view of the phenomenon. Thus, the first phrase requires activities which elicit the student's current mental structures. People always have common-sense concepts, intuitions, or general rules-of-thumb for exploring anything new. These are what must be elicited by the first phase of the worksheet, because it is only from these mental constructs, that intellectual change can proceed. The problem itself only comes into consciousness as a result of questions that force upon the student the inadequacy of his or her present conceptions. This is the worksheet's second phase. It must throw the student into a state of intellectual disequilibrium. Conflict between obdurate phenomena 
and unsophisticated theories must make the student feel the problem in all of its perplexing force, and lead him or her to want to solve it.

It is not enough to perplex students and leave them hanging. Relevant information, guides, questions, and examples must be provided so that the students have a reasonable chance of making new distinctions and typing ideas together in a different way. Activities which lead to intellectual restructuring mark the third phase, which should result in the creation of a new mental equilibrium. The teacher must strike a balance between withholding too much information, on the one hand, and giving out a pre-packaged solution, on the other. Repeated experience in workshops watching students restructure their ideas will guide most teachers to this balance.

In Eloise, the single problem which organizes the activities is this: How can we describe the system of mutual implications between views of child rearing and conceptions of social organization? As a question this is very abstract and is unlikely to lead to a productive discussion. With this problem serving as a focus, the teacher must ask: What activities or tasks would be most likely to lead students to understand these implications? In this case, the authors decided to use a categorizing task. By articulating different ways in which a view of child development contains a conception of society (or vice versa), students will be forced to make distinctions and ask questions that are new to them. The workshop now has a central activity, one that will constitute the second phase (disequilibrium) of the three-phase structure. Sorting quotes almost inevitably reveals the inadequacy of students' intuitive views about children and society and may well produce intellectual conflict as the students argue over which cards belong in which piles and why. Indeed, the card sorting is the center of this workshop, and will perplex students and challenge their current thinking.

However, to present the student with fourteen wordy quotes with no preparation might well throw them too far off balance. First, they need to have their own ideas about children and society elicited in a more familiar and concrete context. The questions about Eloise's diary fulfill this function. By the end of Part I, the students' own ideas should have been articulated, clarified, and written, so they can face the test of the card sorting. 
If the workshop were to end after Part II, the students would have only their own shaky products, the set of categories, which might well seem ad hoc and of little significance. The students now need to use the categories, applying them to phenomena to see if they shed new light. In addition, they need to bring their ideas into the public arena of the class to present them to their peers and teacher. Parts III and IV of Eloise address these needs; they supply the resolution and closure to the experience. Certainly a total restructuring of ideas will not occur as a result of Eloise, but a first step will be made in the process. After the groups have compared their categories in Part IV, they will try to resolve their differences though synthesis in the ensuing discussion. Their original ideas (e.g., about free children and harsh societies) will have been shaken, and they will be on their way toward a more refined and complex system of ideas.

In all this it is important to remember that, intellectual or otherwise, a genuine experience has a style and a texture as well as an organization. Matters of rhythm and timing must not be neglected. Moreover, it is essential that the worksheet not speak to the students in a voice that is didactic or pedantic; it should speak in the author's natural voice. The finished worksheet should bear the teacher's personal stamp, reflecting a sense of play and purpose. Eloise requires students to shift activities repeatedly: It does not try to exhaust the meaning contained in any one source; it progresses, allowing for student work in new modes and in new combinations. The authors attempt to write in the style of a sixth grade girl and provide physical props, the cards with quotes, so that some of the action can be physical. The important point to remember when you are composing a worksheet is that students will actually be doing the things you ask of them, and you must try to envision what it would be like to experience the activities you are designing.

Teacher. In writing a worksheet you have provided a blueprint for an experience. By working backwards from the products of your discipline to activities for students, you have drawn on some of your most creative an pedagogic impulses. Yet your presence at the workshop itself will still be necessary, both to facilitate the students' interaction with the worksheet and to give you the necessary information upon which to base future worksheets. However, your role will 
be quite different from that of the conventional teacher. Most teachers are held captive by the need to continually direct and organize the activities of the class. The students' attention is almost always focused on the teacher. He or she is bound in place by the students' conviction that the teacher is the vital link between themselves and the subject matter. This traditional role puts the teacher at the hub of the wheel, the common source of support and cohesion. In contrast, the teacher's role in the workshop may be summarized by the phrase: The teacher is there, but out of the middle.

In a workshop, it is the worksheet, and not you, which provides the "carrying energy" for the students' work. They are in direct contact with the material and one another, so that you remain outside of their immediate experience. This is just what you need in order to be free to move around and respond to groups of students in a flexible fashion, tailoring your contribution to the needs of the moment. No matter how exquisitely you have designed your worksheet, some students will become stranded in irrelevant details, while others will skim over all that is interesting. Still other students will approach the problem from a point of view you never imagined. All of these students, and many others as well, will benefit from direct interaction with you. As you engage them, getting them started again, deepening their approach or leading them to a new angle of attack, you will feel the most immediate gratification of the sharing of intellectual experiences.

To Summarize, the six principles of design are the following:

Environment:

1. The shared event must be specific, concrete, and present.

2. Specific questions and instructions must be written in advance and given to each student.

3. The teacher should exploit the potential of the group.

Activities:

4. The worksheet must have within it an underlying problem to be solved. To make the problem genuine and solvable requires activities which:

(a) elicit current mental structures;

(b) point to the inadequacy of present structures;

(c) lead to intellectual restructuring.

5. The workshop must have the texture of a genuine experience. 


\section{Teacher:}

6. The teacher is there, but out of the middle.

\section{Diverse Applications}

We cannot convey in this brief article the variety of forms that workshops and worksheets may take. The interested reader should refer to our more complete treatment of the subject ${ }^{1}$ where numerous examples are given, as well as more detailed guidelines for designing workshops. To suggest this variety, we present here several examples of workshops written by us, and our colleagues. Many of these have been composed in collaboration, because we have found that the most effective method of converting intellectual products into activities is for an expert in the subject to join forces with an intellectually inquisitive but naive partner.

1. Hot Tips: An exercise that starts with graphs of the prices of four stocks and moves toward an understanding of rate of change at a point-used in a calculus course for social science majors.

2. The Ideal Gas Law: A reconstruction of the Ideal Gas Law in chemistry, which starts with questions about balloons and pistons, and progressively builds toward an understanding of the regularities stated mathematically in the law-used in an introductory chemistry course.

3. Examination of Assumptions: An exercise in philosophical analysis, based on the extraction of assumptions in a fellow student's written argument, and using several written exchanges between the two partners-used in an introductory philosophy course.

4. How Children Form Mathematical Concepts: A set of questions used to help students digest a Scientific American article read prior to the workshop and brought with them to class - used in an advanced developmental psychology course.

5. The Problem of Identity in "A View From the Bridge": An exercise in applying to the characters in a play a psychological concept previously studied, based on the students' re-creation of each character's point of view in a closing monologue-used in an interdisciplinary social science and humanities course. 
Workshops can fulfill quite a variety of functions within a course. The following is a partial list. ${ }^{2}$

1. Have students parallel the work of an author before reading about that work.

2. Help students gather and organize a wealth of detailed and confusing information.

3. Articulate an intellectual structure by providing a shift of context.

4. Give practice translating between languages within a discipline to show the power of a new language.

5. Help students crystallize their knowledge in preparation for a test.

6. Let students experience physically something they have studied or will study more abstractly.

\section{Conclusion}

We began by addressing a question all teachers must eventually face: Why teach? We have ended with a proposal for improving instruction, a response to the question: How can I improve the learning that takes place in my class? We believe that these two questions are inextricably linked. Many teachers are quick to make superficial changes in their courses, employing new curricular packages, new kinds of tests, and new texts, in the hope of improving their students' education. We are proposing an alteration in the very structure of the teacher's experience with students. To suggest such a step would be futile without addressing a teacher's most basic needs and hopes. We focused on the goal of sharing intellectual experiences because we have found in our own collaboration with numerous teachers that it is precisely this consequence of designing and running workshops that is so gratifying and sustaining. Calling for such broad and unspecified goals as "significant educational change" or "faculty development" strikes us as unproductive because such sweeping appeals do not address teachers' immediate desires. Teachers don't want to "develop"; they want to have intellectual exchanges with their students in a way that lets them see their students' progressive understanding . We have proposed one way of creating such exchanges, one that we 
believe is a significant educational innovation, and one that does result in development- for students and for teachers, too.

We have listed elsewhere ${ }^{3}$ the detailed benefits to students and teachers of this workshop approach. Here we can only summarize by saying that virtually all college students with whom we have worked have thrived in workshops. Because their teachers have removed themselves from "the middle," they have been able to apply their own intellectual powers to concrete problems, thus gaining an awareness of and a confidence in their own intelligence. Moreover, because their teacher's expertise has not been withheld, the students have felt neither abandoned nor manipulated. Able to interact with an environment constructed by their teacher and to work together in a collaborative atmosphere with their peers, they have made conceptual advances that have altered their mental landscape.

One of the dramatic consequences for teachers who write worksheets first and run workshops based on them is their strikingly sharper view of the effects of their pedagogical thinking on students. Having completed the intellectual work before the workshop, teachers can then see more clearly the quality of their students' thinking. Such a vantage leads to a ready understanding of how better to design the next workshop. Moreover, in having to work backwards from the intellectual products of their discipline to the activities that lead to them, teachers find they have to rethink many fundamental questions in their field. Their own intellectual excitement in this process parallels the students' enthusiasm in accomplishing the workshops. And within this interactive cycle occurs the genuine sharing of intellectual experience.

\section{References}

Finkel, Donald L. and Monk, G. Stephen, Contexts for Learning: A Teacher's Guide to the Design of Intellectual Experience. Olympia. WA: The Evergreen State College, 1978.

\section{Suggested reading list:}

Dewey, John. Democracy and Education, Free Press, 1966.

Kohlberg, Lawrence and Mayer, Rochelle. "Development as the Aim of Education," Hanard Education Review, 42, (1972): 449-496.

Furth, Hans. Piaget for Teachers. Prentice Hall, 1970. 
${ }^{1}$ Finkel, Donald L. and Monk, G. Stephen. Contexts for Learning: A Teacher's Guide to the Design of Intellectual Experience. Olympia, WA: The Evergreen State College, 1978.

${ }^{2}$ See Finkel and Monk, Contexts for Learning. pp. 38-43 for amplification.

${ }^{3}$ Finkel and Monk, Contexts for Learning. pp. 99-108. 